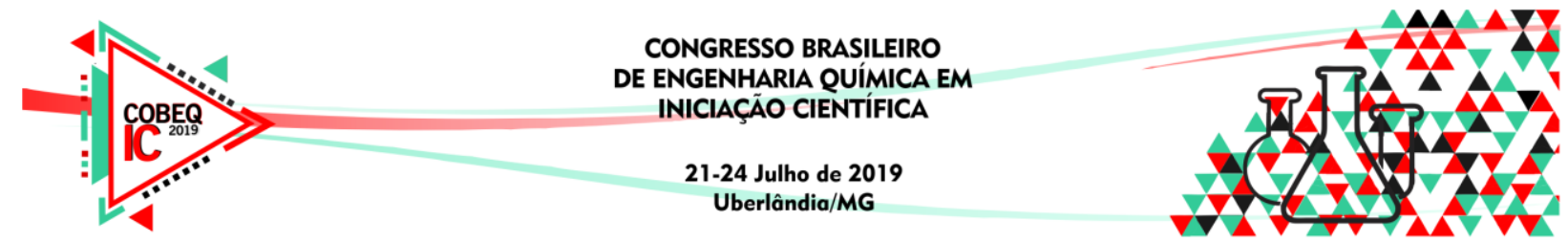

\title{
AVALIAÇÃO DA ATIVIDADE PREBIÓTICA DE XILOOLIGOSSACARÍDEOS (XOS) BRUTO E PRÉ- PURIFICADO OBTIDOS DOS PRÉ-TRATAMENTOS HIDROTÉRMICO E ORGANOSSOLVE DO BAGAÇO DE CANA-DE-AÇÚCAR
}

\author{
J. V. M. MARÇAL ${ }^{1}$, T. S. MILESSI ${ }^{1,2}$ e R. L. C. GIORDANO ${ }^{1}$ \\ ${ }^{1}$ Universidade Federal de São Carlos, Departamento de Engenharia Química \\ ${ }^{2}$ Universidade Federal de Itajubá, Instituto de Recursos Naturais \\ E-mail para contato: thais.milessi@unifei.edu.br
}

\begin{abstract}
RESUMO - Probióticos são microrganismos vivos que conferem benefícios à saúde, sendo seu crescimento estimulado por substâncias prebióticas. Xilooligossacarídeos (XOS) são oligômeros de xilose de alto valor agregado dado seu potencial prebiótico, os quais podem ser produzidos a partir de subprodutos agro-industriais, como o bagaço de cana-de-açúcar, utilizando-se um processo de pré-tratamento brando associado a uma hidrólise enzimática. Desta forma, o perfil de XOS produzido dependerá do pré-tratamento, das xilanases e das características do substrato utilizados. Nesse contexto, o objetivo do presente trabalho foi avaliar a atividade prebiótica dos diferentes XOS obtidos do bagaço de cana-de-açúcar pelos pré-tratamentos hidrotérmico e organossolve. Para isso, os pré-tratamentos hidrotérmico e organossolve foram realizados em condições pré-estabelecidas $\left(185^{\circ} \mathrm{C} / 10 \mathrm{~min}\right.$ e $170^{\circ} \mathrm{C} / 60 \mathrm{~min} / 50 \%$ etanol, respectivamente) e os licores obtidos foram concentrados e submetidos à ação de uma xilanase préselecionada. Os XOS produzidos foram utilizados na suplementação de meio MRS utilizado no crescimento de L. reuteri. Os XOS hidrotérmicos apresentaram significativa atividade prebiótica, estimulando o crescimento celular das bactérias, ao contrário dos XOS organossolve. Além disso, foi realizado um teste preliminar de purificação no XOS hidrotérmico em coluna C18 com o intuito de remover inibidores, fato que favoreceu o crescimento da bactéria, aumentando a biomassa celular em $38 \%$.
\end{abstract}

\section{INTRODUÇÃO}

O desafio do mercado de alimentos atualmente é investir em tecnologias de biopreservação e alimentos funcionais, que promovem a saúde e o bem-estar, em detrimento da utilização de conservantes químicos e alimentos processados. Nesse cenário, a utilização de probióticos nos alimentos emerge cada vez mais como alternativa promissora (Quinto et al, 2014).

Probióticos são microrganismos vivos que, quando ingeridos em concentrações adequadas, conferem benefícios à saúde do hospedeiro (Nogueira, 2011). Os probióticos mais 


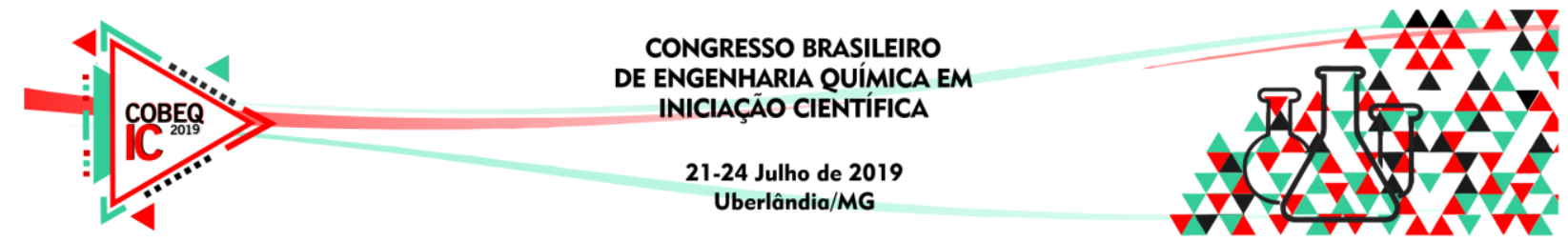

utilizados comercialmente são as bactérias ácido láticas, como os lactobacilos, uma vez que eles estimulam o bom funcionamento da flora intestinal e sintetizam diversos metabólitos com propriedades antimicrobianas, como ácido lático e bacteriocinas (Nascimento et al., 2008). O crescimento desses microrganismos é favorecido pelo consumo de substâncias prebióticas, as quais são definidas como componentes alimentares não-digeríveis que afetam beneficamente o hospedeiro, por estimularem seletivamente a proliferação ou atividade de bactérias desejáveis no trato gastrointestinal (Saad, 2006).

Xilooligossacarídeos (XOS), por sua vez, são oligômeros pequenos de xilose (2-7 unidades) de alto valor agregado por possuírem propriedades prebióticas. Dentro do contexto atual de biorrefinaria, estes compostos podem ser obtidos a partir de materiais lignocelulósicos, como o bagaço de cana-de-açúcar. Para a obtenção de XOS, a hemicelulose deve ser extraída da biomassa lignocelulósica através de uma etapa de pré-tratamento de forma branda, gerando oligômeros com a mínima formação de xilose (Carvalho et al, 2013). Nesta etapa, pode ocorrer a formação de inibidores, como furfural e hidroximetilfurfural, devido a degradação da biomassa, podendo ser necessária uma etapa de destoxificação do hidrolisado para remoção destes inibidores (Hamelinck et al, 2005). Na sequência, uma hidrólise enzimática controlada é conduzida por endoxilanases, levando a formação de XOS (Dodd e Cann, 2009).

O perfil de XOS obtidos irá depender da xilanase e biomassa utilizadas, uma vez que a cadeia lateral da xilana é reconhecida pelas xilanases, e essas ramificações influenciam a ação destas enzimas (Carvalho et al., 2013). O tipo de pré-tratamento empregado também irá influenciar significativamente na produção de XOS. De acordo com Rodrigues-Zúñiga et al. (2014), os pré-tratamentos hidrotérmico e organossolve apresentam maior solubilização de hemicelulose na forma de oligômeros e, portanto, foram utilizados no presente trabalho. Posto isto, o presente trabalho teve como objetivo de avaliar a atividade prebiótica de XOS obtidos pelos pré-tratamentos hidrotérmico e organossolve em sua forma bruta e pré-purificada.

\section{MATERIAIS E MÉTODOS}

\subsection{Materiais}

Os materiais utilizados foram: bagaço de cana-de-açúcar (teor de umidade 50\%) gentilmente fornecido pelo Centro de Tecnologia Canavieira (CTC, Piracicaba, Brasil); xilana comercial de milho (Carl Roth-Alemanha); coluna SEPAK C18 (Waters, USA); meio MRS (Sigma-Aldrich SA, USA); endoxilanase NS22036 (Novozymes, Dinamarca) e a bactéria $L$. reuteri (Aquativa, São Carlos, Brasil). Todos os demais reagentes utilizados foram de grau analítico.

\subsection{Métodos}

Pré-tratamento: Os pré-tratamentos hidrotérmico e organossolve foram realizados em reator de alta pressão Parr (2L). No processo hidrotérmico foram utilizadas condições de $185^{\circ} \mathrm{C}, 10$ min e relação sólido:líquido de $1: 10(\mathrm{~m} / \mathrm{v})$. O processo organossolve foi realizado 


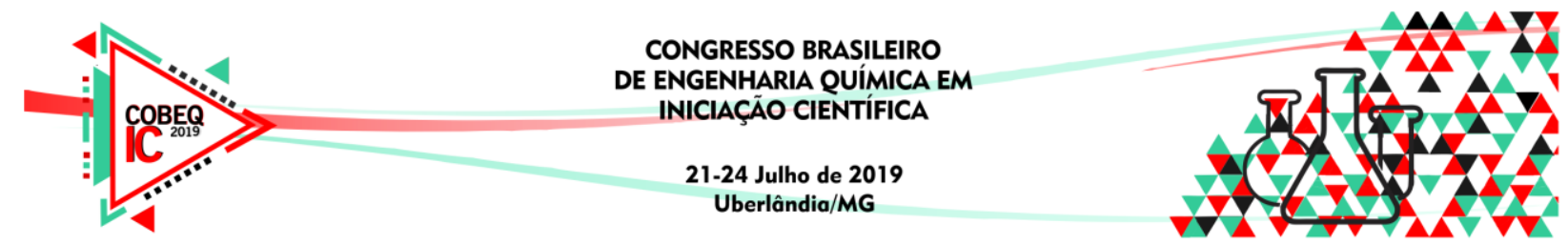

em condições pré-estabelecidas por Manrich $(2012)$ a $170^{\circ} \mathrm{C}$ durante $60 \mathrm{~min}, 50 \%$ etanol (v/v) e relação sólido:líquido 1:10 (m/v). Ao final do processo, o bagaço foi filtrado ainda quente para evitar a precipitação da lignina solubilizada. O licor negro obtido, teve o etanol evaporado em rotoevaporador a $70^{\circ} \mathrm{C}$.

Hidrólise enzimática dos licores: Os licores hidrotérmico e organossolve brutos obtidos foram concentrados em rotoevaporador à $70^{\circ} \mathrm{C}$ a fim de se obter uma concentração de $25 \mathrm{~g} / \mathrm{L}$ de Xilooligômeros. A hidrólize enzimático foi realizada utilizando-se $3,8 \mathrm{UI} / \mathrm{ml}$ reator da xilanase NS22036, durante 24 horas nas condições de $50^{\circ} \mathrm{C}$ e pH 5,5.

Avaliação da atividade prebiótica dos XOS: Os lactobacilos foram mantidos a $-80^{\circ} \mathrm{C} \mathrm{em}$ caldo MRS com $20 \%$ (v/v) de glicerol. Um pré-inóculo foi realizado para propagação das bactérias em meio MRS, o qual foi mantido em incubadora a $37^{\circ} \mathrm{C}$ por 18 horas. A partir do cultivo do pré-inóculo, os lactobacilos foram inoculados com DO inicial 0,05 em meio MRS suplementado com XOS (1:5) e incubados a $37^{\circ} \mathrm{C}, \mathrm{pH} 6,0$ por $24 \mathrm{~h}$ (ROSA, 2001) e o crescimento celular foi avaliado.

Medida das concentrações de XOS: XOS foram analisados por Cromatografia Líquida de Alta Eficiência (CLAE) utilizando um cromatógrafo Waters e2695 equipado com coluna Sugar-PakTMI $(300 \times 6,5 \mathrm{~mm})$ com água ultra pura como fase móvel num fluxo de 0,6 $\mathrm{mL} / \mathrm{min}$, temperatura de $80^{\circ} \mathrm{C}$ e detectores de índice de refração e UV-visível. Antes das análises, as amostras foram devidamente filtradas em membranas de $0,2 \mu \mathrm{m}$ e em filtros SepPak® C-18 (Waters) para remoção de derivados da lignina e outros produtos de degradação.

Medida da concentração de células: A concentração de células de Lactobacilos foi determinada por turbidimetria em espectrofotômetro a $600 \mathrm{~nm}$, e correlacionada com o peso seco de células $(\mathrm{g} / \mathrm{L})$ através de uma curva de calibração correspondente. As medidas foram feitas em suspensões celulares devidamente diluídas, após centrifugação, lavagem e ressuspensão das células em água destilada.

\section{RESULTADOS}

Os XOS produzidos a partir dos pré-tratamentos hidrotérmico e organossolve apresentaram perfis diferentes de composição (Tabela 1), sendo que o pré-tratamento hidrotérmico apresentou maior produção de xilobiose e xilotriose.

Tabela 1 - Perfis de XOS produzidos após 24h de hidrólise enzimática dos licores hidrotérmico e organossolve $\left(150 \mathrm{UI} / \mathrm{g}_{\text {xilana, }}, 3800 \mathrm{UI} / \mathrm{L}, 50^{\circ} \mathrm{C} \mathrm{pH} 5,5\right)$.

\begin{tabular}{|c|c|c|c|c|c|c|}
\hline Pré-tratamento & X6 $(\mathrm{g} / \mathrm{L})$ & $\mathrm{X} 5(\mathrm{~g} / \mathrm{L})$ & $\mathrm{X} 4(\mathrm{~g} / \mathrm{L})$ & $\mathrm{X} 3(\mathrm{~g} / \mathrm{L})$ & $\mathrm{X} 2(\mathrm{~g} / \mathrm{L})$ & Xilose $(\mathrm{g} / \mathrm{L})$ \\
\hline \hline Hidrotérmico & 3,7 & 2,35 & 3,32 & 5,65 & 5,62 & 3,54 \\
\hline Organossolve & 3,8 & 2,2 & 1,9 & 3,2 & 3,3 & 2,8 \\
\hline
\end{tabular}

X2: xilobiose; X3: xilotriose; X4: xilotetraose; X5: xilopentaose; X6: xilohexaose 


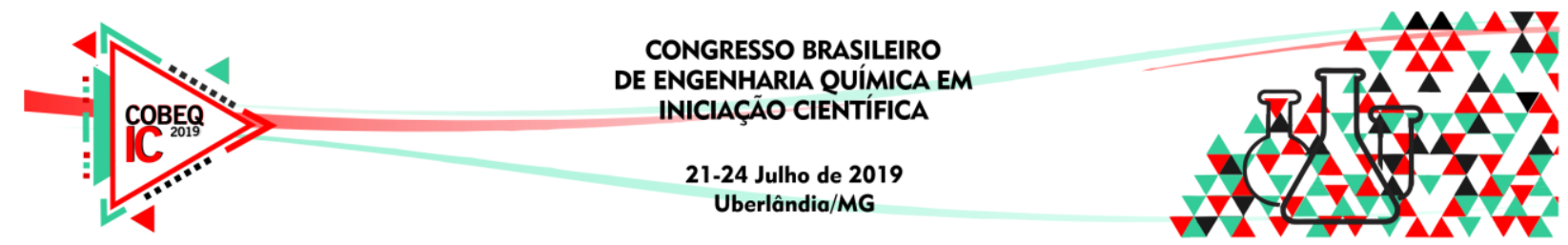

A capacidade prebiótica dos XOS obtidos a partir dos licores hidrotérmico e organossolve do bagaço de cana-de-açúcar foi avaliada pela sua influência no crescimento de lactobacilos. Utilizou-se xilana comercial de milho contendo $25 \mathrm{~g} / \mathrm{L}$ de XOS como controle positivo, a qual correspondia aos XOS sem a presença dos inibidores dos licores. Já como controle negativo foi utilizado meio MRS sem a adição de XOS. Além dos controles positivo e negativo, também testou-se os licores hidrotérmico e organossolve sem terem sido hidrolisados enzimaticamente, ou seja, brutos sem XOS.

Os inibidores gerados pelos pré-tratamentos (furfural e hidroximetilfurfural) afetaram o crescimento microbiano. Isso é comprovado pelos dados da Tabela 2, visto que o crescimento nos hidrolisados hidrotérmico e organossolve brutos foram menores do que nos meios MRS e na xilana de milho, os quais não possuem inibidores. No entanto, os XOS produzidos na hidrólise enzimática contornaram a inibição, uma vez que o crescimento no hidrolisado hidrotérmico com XOS foi maior do que no hidrolisado hidrotérmico bruto. Já os XOS organossolve não apresentaram capacidade semelhante, não havendo melhoria do crescimento bacteriano em sua presença.

Tabela 2 - Acompanhamento do cultivo de L. reuteri em meio MRS suplementado com diferentes $\mathrm{XOS}\left(37^{\circ} \mathrm{C}, \mathrm{pH}\right.$ 6,0 e $\left.50 \mathrm{rpm}\right)$

\begin{tabular}{|c|c|c|c|}
\hline Meio & DO $(24 h)$ & Furfural $(\mathrm{g} / \mathrm{L})$ & HMF* $(\mathrm{g} / \mathrm{L})$ \\
\hline \hline XOS hidrotérmico & $4,40 \pm 0,04$ & 0,01 & 0,4 \\
\hline XOS hidrotérmico purificado & $5,96 \pm 0,04$ & 0 & 0 \\
\hline Hidrotérmico bruto & $2,75 \pm 0,03$ & 0,01 & 0,4 \\
\hline XOS organossolve & $2,98 \pm 0,02$ & 0,02 & 0,54 \\
\hline Organossolve bruto & $2,74 \pm 0,17$ & 0,02 & 0,54 \\
\hline Controle $(-)$ & $4,19 \pm 0,07$ & 0 & 0 \\
\hline Controle $(+)$ & $5,14 \pm 0,02$ & 0 & 0 \\
\hline
\end{tabular}

*HMF: hidroximetilfurfural

Devido ao potencial apresentado, os XOS hidrotérmicos foram purificados em coluna C-18 para adsorção dos compostos inibidores. Os dados da Tabela 2 mostram que os XOS purificados estimularam ainda mais o crescimento microbiano, aumentando a densidade ótica de 4,40 para 5,96. Fica evidente que a purificação dos XOS de bagaço de cana é necessária antes de sua aplicação no cultivo de lactobacilos.

\section{CONCLUSÕES}

Diferentes métodos de pré-tratamento podem produzir XOS com propriedades diferentes, a partir da mesma matéria-prima. Os XOS obtidos utilizando-se o pré-tratamento hidrotérmico apesentaram atividade prebiótica significativa, auxiliando na superação do efeito inibitório de compostos como furfural e HMF. Por fim, XOS de bagaço de cana podem ser prebióticos promissores, necessitando, porém, de uma etapa de purificação, a qual necessita ser otimizada em estudos futuros. 


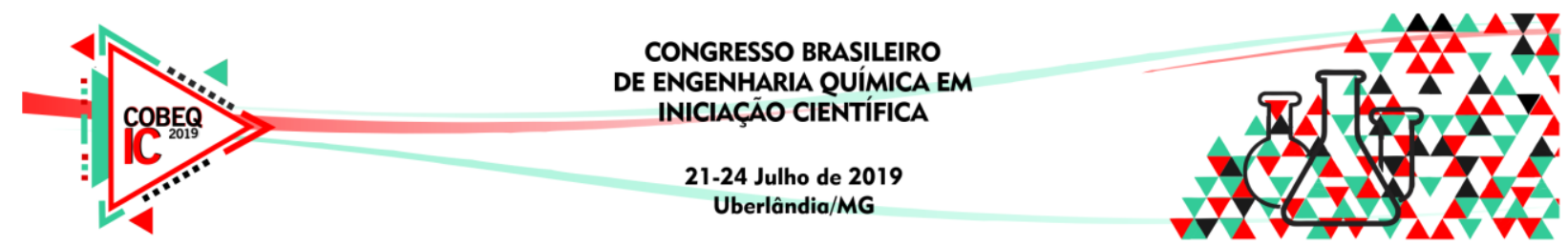

\section{AGRADECIMENTOS}

Os autores agradecem a Fundação de Amparo à Pesquisa do Estado de São Paulo (2016/10.636-8 e 2018/14552-9) e o Conselho Nacional de Desenvolvimento Científico e Tecnológico (CNPq).

\section{REFERÊNCIAS}

CARVALHO, A. F. A; NETO, P. O; SILVA D. F; PASTORE, G. M. Xylo-oligosaccharides from lignocellulosic materials: Chemical structure; health benefits and production by chemical and enzymatic hydrolysis. Food Res. Int., v. 51, p. 75 - 85, 2013.

DODD, D; CANN, I.K.O. Enzymatic deconstruction of xylan for biofuel production. $G C B$ Bioenergy, v.1, p.2-17, 2009.

HAMELINCK, C.N.; HOOIJDONK, G.V.; FAAIJ, A.P.C. Ethanol from lignocellulosic biomass: techno-economic performance in short-, middle- and long-term. Biomass Bioenergy, v. 28, p. 384-410, 2005.

MANRICH, A. Produção de xilo-oligossacarídeos a partir de lignocelulósicos pré-tratados com xilanases imobilizadas e estabilizadas. Tese de doutorado, Universidade Federal de São Carlos, Fevereiro de 2012.

MUSSATTO, S.I.; DRAGONE, G.; GUIMARÃES, P.M.R.; SILVA, J.P.A.; CAMEIRO, L.M.; ROBERTO, I.C.; VICENTE, A.; DOMINGUES, L.; TEIXEIRA, J.A. Technological trends, global market and challenges of bio-ethanol production. Biotechnol. Adv., v. 28, p. 817-830, 2010.

NASCIMENTO, M. S; MORENO, I; KUAYE, A. Y. Bacteriocinas em alimentos: uma revisão. Braz. J. Food Preservation, v. 11, n. 2, p. 120-127, 2008.

NOGUEIRA, J.C.R.; GONÇALVES M.C.R. Probióticos - Revisão da Literatura. Revista Brasileira de Ciências da Saúde, v. 15, 4 ed, p. 487-492, 2011.

QUINTO, E.J., JIMÉNEZ, P., CARO, I., TEJERO, J., MATEO, J. AND GIRBÉS, T. Probiotic Lactic Acid Bacteria: A Review. Food Nutri. Sci., v. 5, p. 1765-1775, 2014

RODRÍGUEZ-ZÚÑIGA, U.F.; FARINAS, C.S.; CARNEIRO, R.L.; SILVA, G.M.; CRUZ, A.J.G.; GIORDANO, R.L.C.; GIORDANO, R.C.; RIBEIRO, M.P.A. Fast Determination of the Composition of Pretreated Sugarcane Bagasse Using NearInfrared Spectroscopy. Bioenerg. Res., v. 7, p. 1441-1453, 2014.

ROSA, C.M. Purificação e Mecanismo de ação de uma bacteriocina produzida por Lactobacillus sake 2a isolado de linguiça frescal. Tese de Doutorado, São Paulo, Brasil. Universidade de São Paulo, 2001.

SAAD, S. M. I. Probióticos e prebióticos: o estado da arte. Revista Brasileira de Ciências Farmacêuticas. v. 46, n. 1, 2006. 